\title{
Does working from home reduce CO2 emissions? An analysis of travel patterns as dictated by workplaces
}

\author{
Eugênia Dória Viana Cerqueira $^{\mathrm{a}, *}$, Benjamin Motte-Baumvol ${ }^{\mathrm{a}}$, \\ Leslie Belton Chevallier ${ }^{\mathrm{b}}$, Olivier Bonin ${ }^{\mathrm{c}}$ \\ ${ }^{a}$ Université Bourgogne Franche-Comté, UMR CNRS THEMA, France \\ ${ }^{\mathrm{b}}$ AME-DEST, Université Gustave Eiffel, France \\ ${ }^{\mathrm{c}}$ LVMT, Université Gustave Eiffel, France
}

\section{A R T I C L E I N F O}

\section{Keywords:}

Emissions distribution

Travel behavior

Telecommuting

Commuting

Sustainable transport

\begin{abstract}
A B S T R A C T
This research provides new evidence about the relationship between travel behavior, workplace diversification, and environmental impact in the United Kingdom using data from the National Travel Survey for the period between 2002 and 2017. The path analysis approach based on SEM handles both direct and indirect effects and allows for a comprehensive study of travel behavior, trade-off effects, and work and non-work trips. The results suggest that workplace diversification is often reflected by longer average distances for work trips, which are often associated with more remote residential locations. Findings also show that for some categories, such as teleworkers and home-based workers, trade-off effects are observed between work and non-work trips, which increase $\mathrm{CO} 2$ emission levels.
\end{abstract}

\section{Introduction}

A number of key developments have affected the labor market over recent decades. These include the increased participation of women in the labor force, the changing nature of the employer-employee relationship, and the growing role of information and communication technologies (ICT). These developments have tended to modify daily work patterns in terms of both time-schedules and workplace locations. The changes in the working day and, in particular, the diversification of workplaces (as with teleworking) may potentially contribute to a strategy for managing travel demand so as to reduce congestion and the negative environmental impacts of transportation such as greenhouse gas emissions (GHG). Nonetheless, studies of teleworking tend to identify a series of rebound effects, such as the trade-off between commuting and non-work trips, or residential relocation (Ory and Mokhtarian, 2006; Ravalet and Rerat, 2019). Although previous scholars have explored the impacts of telework on travel patterns, few studies have highlighted how other changes in the workplace, such as multiple work locations or home-based work (Mokhtarian and Henderson, 2000) might affect travel behavior.

Commuting and business-related trips aside, the changes affecting workplaces also have significant effects on non-work trips. Work location and schedules play a structuring role in the daily activity program and are likely to affect other trip purposes as well, such as shopping, recreational, and health-related trips (Aguilera et al., 2009). On the one hand, a large proportion of individuals' non-work trips are undertaken in conjunction with work-related travel. On the other hand, the development of ICT increases the

\footnotetext{
* Corresponding author.

E-mail addresses: eugeniadoria@gmail.com (E.D.V. Cerqueira), benjamin.motte@u-bourgogne.fr (B. Motte-Baumvol), leslie.belton-chevallier@univ-eiffel.fr (L.B. Chevallier), olivier.bonin@univ-eiffel.fr (O. Bonin).
} 
porosity between work and non-work activities, creating more complex travel patterns (Schieman and Young, 2010). Therefore, this paper aims to evaluate the impacts of the changing nature of workplaces on travel behavior and, consequently, its environmental effects. The underlying research question is: Does the evolution of workplace locations (teleworking, working at home, multiple workplaces) contribute to restructuring travel patterns and reducing CO2 emissions? The "teleworkers" group accounts for individuals who do not identify themselves as "homeworkers" and who declared they worked from home "three or more times a week" or "once or twice a week", while home-based workers are defined as individuals whose main place of work is at home or in the same building as their home.

Thus, we investigate the relationship between workplace, travel behavior, and $\mathrm{CO} 2$ emissions, based on travel survey data for the United Kingdom (NTS 2002-2017 dataset), which collects data from trip diaries for each surveyed household during a week. The seven-day observation period provides a much more representative picture than traditional one-day travel surveys do.

The main findings are based on Structural Equation Modeling (SEM) implementing path analysis and notably highlight the effects of homeworking on travel behavior and related $\mathrm{CO} 2$ emissions. Results show that individuals who work at home travel more kilometers in total for non-work trips on weekdays. Thus, the CO2 emission levels corresponding to the total weekly trips of home-based workers are higher than for those working in a fixed non-home-based place. Moreover, teleworkers are responsible for the highest CO2 emission levels, as they tend to run up a higher number of kilometers traveled for both work and non-work trips. Trade-off effects are observed, as teleworkers tend to offset commuting trips against non-work travel on telework days.

The article is structured as follows. In Section 2, previous studies of the change of workplace and its impacts on travel behavior are reviewed. The case for focusing on the influence of work on non-work trips is also made, and previous contributions in this area are summarized. Section 3 presents the approach and the data and it briefly describes the modeling method used. Results are presented in Section 4 and Section 5 provides a discussion of the main conclusions and some lessons that can be drawn for future studies.

\section{Literature review}

\subsection{Changes in the workplace and travel behavior}

In recent years, scholars have drawn attention to the growing diversification of workplaces and the notion that the world of work is spreading through time and space. Working hours have become less standardized and work can be done in a myriad of places, at the office, at home, on the train, at a coffee shop (Felstead, 2012). Over the past two decades, the proportion of individuals who work in a fixed workplace has declined continually, and now concerns certain jobs to a much greater extent than others (e.g., manufacturing jobs). Although this category remains the majority among all groups of workers, alternative work arrangements, such as multi-location work and home-based work (in different forms), now make up a growing component of the labor market. Lesnard and Kan (2011) provide important insights into the de-standardization of working patterns. Those authors demonstrate that standard workdays account for just over a half of total workdays, and standard workweeks constitute about a fourth of workweeks in the United Kingdom between 2000 and 2001.

Recent developments in ICT have eroded the spatial fixity of the workplace, allowing more individuals to work from home, either permanently or several times a week. Telework has benefitted from improvements in information and communication technologies, and it was expected to be a potential way of reducing travel demand and, consequently, congestion and greenhouse gas (GHG) emissions. Findings show that teleworking is a strategy often used by individuals to mitigate the cost and time spent commuting (De Abreu e Silva and Melo, 2018). Thus, workers living in low-density areas and with longer commutes tend to telework more frequently. However, teleworkers tend to have longer commutes than their non-teleworker counterparts, which means that they tend to live further from the workplace (Ory and Mokhtarian, 2006; Zhu, 2013). Reducing the frequency of commuting seems to allow teleworkers to accept longer commute distances (Ettema, 2010; Zhu, 2013).

The positive effects of telework, such as the reduction in the number of trips and kilometers traveled, have been actively supported by policymakers and demonstrated by some scholars (Choo et al., 2005; Helminen and Ristimäki, 2007). More recently, several studies have indicated the limited impact of teleworking on reducing kilometers traveled and GHG emissions, and they have also identified a variety of rebound effects ( $\mathrm{He}$ and Hu, 2015). Findings suggest that while telework may reduce travel costs and time, the time saved on commuting may be used to engage in other activities and be converted into additional personal non-work trips or longer trips (Mokhtarian, 2009; Zhu, 2012; Zhu and Mason, 2014). Thus, telecommuters may drive more for both daily work and non-work trips than non-telecommuters (Volosin et al., 2013). Workers who are able to work from home report longer travel time, often because they are in higher-paying managerial and professional positions or live farther from work. Moreover, recent studies have demonstrated that households with at least one teleworker tend to travel more and have larger travel budgets than other households do (Melo and de Abreu e Silva, 2017).

Though telework has been a trending topic in the scholarly literature, few studies have focused on travel patterns of home-based workers (non-teleworkers). Growth in home-based work is related to advances in ICT and also to the increased proportion of contingent and self-employed workers. Mokhtarian and Henderson (2000) demonstrate that home-based business workers make a higher average number of daily trips than non-home-based workers, both for work-related trips and for other purposes such as shopping, social life, and recreation. On the other hand, home-based workers have the lowest average daily travel time and the shortest travel distances. While home-based workers typically might not have traditional commute trips, their work-related travel might still be significant.

Thus, scholars have concluded that individuals who work from home tend to display reduced activity spaces (Pendyala et al., 1991) because their activities tend to be centered around their residence, contrary to what happens for other categories of workers 
whose activities tend to be oriented toward their employment area. Moreover, there is evidence that teleworkers and home-based workers tend to live in more suburban areas and that there is a higher likelihood of their local trips being made by car (Yen, 2000). Although there is evidence that homeworking can reduce emissions related to transport use, Baker and Rylatt (2008) demonstrate that working from home increases domestic energy consumption during the day. Homeworkers need adequate warmth and lighting and usually some electrical equipment for their work, leading to increased energy consumption and CO2 emissions.

Changes in work arrangements also mean that some workers have multiple places of work (Koroma et al., 2014). This often relates to a diversity of occupations: construction workers, artists, executives. The rapid development of mobility over the past decades has allowed workers to access multiple places faster. Most studies analyze commuting trips only, largely ignoring business trips, such as delivering goods and visiting customers. Aguilera et al. (2009) emphasize that, for Greater Paris, workers with multiple workplaces have considerably different travel-behavior than regular commuters with a single workplace. These individuals tend to make more work trips than regular workers. In addition, the authors show that the fact that the average distance traveled for business purposes is short implies that non-regular workplaces are mainly situated close to the main workplace.

\subsection{The influence of work on non-work trips}

Work has been considered to play a key role on how travel patterns are structured: individuals' trips are largely determined by workplace location, work schedules, and trips between home and the workplace. A large proportion of individuals' non-work trips is undertaken in conjunction with work-related travel, which creates a network of multi-purpose trips (Hanson, 1980). However, most studies still contemplate work trips as single straight commuting trips, ignoring the fact that individuals may make stops to shop or use other service activities in conjunction with work-related trips. Thus, it is noteworthy that work-related travel tends to play a major structural role in individuals' travel behavior, including non-work trips: other activities tend to be planned around work, that remains the primary trip purpose (Westelius, 1973). A substantial number of non-work trips are centered around the workplace, around home, or on the journey between the two (Aguilera et al., 2009).

The significant variability in daily travel suggests there is a complex logic behind allocating time to work and non-work activities (Astroza et al., 2018). Some studies have demonstrated that on working days, non-work trips are limited in number and distance by space-time constraints related to work: on working days, non-work trips are usually shorter and more frequently for mandatory activities, such as grocery shopping and escort trips, while on non-working days, non-work travel involves discretionary activities such as leisure, recreation, visiting family, and planned constrained activities such as medical consultations (Soo et al., 2008).

It has been previously noted that long working hours result in less time for travel associated with discretionary activities and greater variability in the number of non-work trips during the week for workers (Tarigan and Kitamura, 2009). Thus, for individuals working long hours, non-work activities, are often limited by the location of discretionary activities and mainly by the location of the workplace. Hence, some non-work trips are made within a short radius around home or the workplace especially during break-time (Aguilera et al., 2009). It appears that long working hours limit and strongly shape non-work trips, in terms of number, distance, and duration.

Furthermore, socio-economic characteristics of workers, at an individual and household level, might influence their travel patterns for non-work activities. Studies have concluded that the presence of children contributes to an increase in the average number of non-work trips, mostly related to escort trips (Aguilera et al., 2009). Likewise, the influence of gender has been confirmed in explaining the average number of daily trips and the average number of non-work trips with female workers tending to make more non-work trips than male workers (Gordon et al., 1989; Fan, 2017).

\section{Data and methods}

\subsection{The NTS survey and GHG emissions}

The data used were obtained from the United Kingdom National Travel Survey (NTS) for the period between 2002 and 2017, in order to ensure a healthy sample size for the non-traditional working patterns, which are relatively rare occurrences. Data used refer to the travel of English residents within Great Britain. The NTS is a continuous household survey of personal travel of UK residents that has been carried out yearly since 1988. Data is collected via interviews from a seven-day trip diary for each individual from a household. Several scholars have demonstrated that one-day data is inadequate to fully explain travel patterns, in particular nonwork trips, which are less frequent and regular than work-related travel. Pas and Koppelman (1987) show that individual variability explains up to $50 \%$ of the number of non-work activities, challenging the ability of many models to predict demand for travel. Axhausen et al. (2002) demonstrate that the most relevant period for studying the frequency of all motives of movement of individuals is two weeks, but that a whole week of travel makes for an acceptable compromise.

Among the individuals surveyed in the NTS, we selected workers over the age of 18 who traveled on at least two days during the survey week. This last condition is designed to remove individuals with extreme mobility from the sample as they could potentially disrupt the statistical models employed. In the end, the sample size is 113,153 observations. In this study, we use five different groups of workers based on their workplace: 1 - workers who work in a fixed place all week (73\%); 2 - workers who work in a fixed place at least two days a week (6\%); 3 - workers who have multiple places of work (11.1\%); 4 - home-based workers (3.8\%); 5 - teleworkers $(6 \%)$.

The different categories of workplaces are defined in the survey on the basis of a main criterion which is the "usual" place of work. This workplace must be "a place they visit on at least two consecutive days per week for at least four consecutive weeks". It is this 
criterion which makes it possible to differentiate those who work away from home, at home, and those who work in different places (do not have a usual place of work). Those who have a usual place of work outside the home, and also a secondary place of work (which may be the home) have been included under the category "go to the same place on at least two days". This traditional categorization of workplaces, which is found in many travel surveys in Europe (Armoogum et al., 2014) presents numerous limitations with regards to changes in the job market. In particular ICT enables individuals to exercise many professional activities outside of a "usual" place of work. Teleworking is one of the notable forms of these changes and its effects on travel-behavior have been already well documented over the last decade (Ravalet and Rerat, 2019; De Abreu e Silva and Melo, 2018). Thus, we opted to include the category of "teleworkers" in our analysis. The "teleworkers" group was created from the variable "How often do you work from home?" We selected individuals who do not identify themselves as "homeworkers" and who declared they worked from home "three or more times a week" or "once or twice a week". This means that the teleworker category in this work is relatively restrictive compared to the definitions that can be found in the literature and includes only individuals with a usual place of work outside of home, i.e., whose teleworking does not exceed three days a week. The teleworkers group is derived mainly from the categories "Same place" and "Different places" (Table 1).

In order to calculate GHG emissions, we applied the DECC \& DEFRA CO2 conversion factors for each trip to the data set using a method similar to that developed by Mattioli and Anable (2017). For private vehicles, we assigned different factors according to vehicle type (car or motorbike), vehicle size (small, medium, large, $4 \times 4$ ) and type of fuel (petrol or diesel). ${ }^{1}$ For trips with more than one passenger we allocated emissions equally among passengers. Heinen and Mattioli (2019) argue that attributing all vehicle emissions to the driver might lead to an underestimation of the emissions of individuals who often travel as passengers, while equally assigning emissions among passengers entails a "leakage" of emissions, as some emissions are attributed to minors. As the sample in this study includes workers only, the choice was to allocate emissions equally among passengers.

We also assigned $\mathrm{CO} 2$ coefficients to trips made by public transport according to the type of mode of transport used (bus, light rail, London Bus). No carbon emissions factor was assigned to cycling and walking trips. Finally, the total CO2 trip emissions were obtained by multiplying the trip distance ${ }^{2}$ by the $\mathrm{CO} 2$ emission factor for each mode of transport. It is important to note that the NTS Survey provides CO2 emission factors derived from the Driver \& Vehicle Licensing Agency (DVLA) dataset, as adopted by Heinen and Mattioli (2019). Nonetheless, the emission factors are not available for the majority of vehicles in the older waves of the survey, leading us to adopt the DECC \& DEFRA CO2 conversion factors.

\subsection{Conceptual framework and SEM model}

The main research questions outlined in this paper are related to the effects of the variety of workplaces on travel behavior and $\mathrm{CO} 2$ emissions. In order to answer these questions, the modeling framework was developed to understand the relationship between socio-economic characteristics and workplaces of the active population, travel patterns, and CO2 emissions. The model seeks to understand the different effects and travel patterns by taking into account the number of weekly trips and the distance traveled. The model is built in two stages. The first stage aims at a better understanding of the link between workplaces and travel patterns, while the second stage measures the effects of travel patterns on $\mathrm{CO} 2$ emissions. It is important to note that the analysis applied the NTS weights.

Structural Equation Modeling (SEM) is used here and has an advantage over classical path analysis via multiple regressions. We can precisely analyze the covariances between the variables, particularly between determined and predictor variables. The estimation is performed in one step via a maximization of the likelihood of the model, allowing for non-spherical error terms. For the first stage of the model, four regressions are used to explain the number of trips and the distances traveled for work (work and in course of work) and non-work trips (other purposes except returning home). The first level is illustrated in the upper part of Fig. 1. The regressions are represented by the four arrows that link the four trip-related variables.

At this stage, travel to return home was ignored. Indeed, the weight of the return home is highly dependent on other trip purposes. The low variability of return-to-home trips relative to all other motives justifies not including these trips in the model. Indeed, they are a function of other trips. This can be verified with the share of home returns in the total number of trips (i.e., an indicator of trip chaining), which varies very little with the type of workplace (Table 2). Thus, their formal inclusion in the model would expose it to problems of multicollinearity, while doing very little to further our understanding of the mechanisms at work.

The explanatory variables are the same for the four regressions and take into account the socio-economic characteristics of workers and their households, including the types of workplace. All of the variables observed come from the UK NTS and are presented in Table 4.

\footnotetext{
${ }^{1}$ Some vehicles did not have an assigned size. An average CO2 coefficient was allocated *vehicles* for which vehicle size was unspecified and, consequently, to all the trip stages that individuals made *using those vehicles.

${ }^{2}$ Trips longer than $80 \mathrm{~km}$ were 'top-coded' as $80 \mathrm{~km}$, which corresponds to the threshold for long-distance journeys in the NTS. The presence of extreme distances could potentially lead to misinterpreted results.
} 
Table 1

Frequency of working from home according to workplace.

\begin{tabular}{|c|c|c|c|c|}
\hline \multirow[t]{2}{*}{ Work place location } & \multicolumn{3}{|c|}{ How often do you work at home? (\%) } & \multirow[t]{2}{*}{ All } \\
\hline & Do not apply & Less than once a week or never & Once or more times a week & \\
\hline Same place & 30.7 & 42.1 & 2.5 & 75.3 \\
\hline Same place on at least 2 consecutive days & 2.1 & 3.8 & 1.1 & 7.0 \\
\hline Different places & 4.4 & 6.8 & 2.6 & 13.8 \\
\hline Home / same building as home & 3.9 & 0.0 & 0.0 & 3.9 \\
\hline All & 41.0 & 52.8 & 6.2 & 100.0 \\
\hline
\end{tabular}

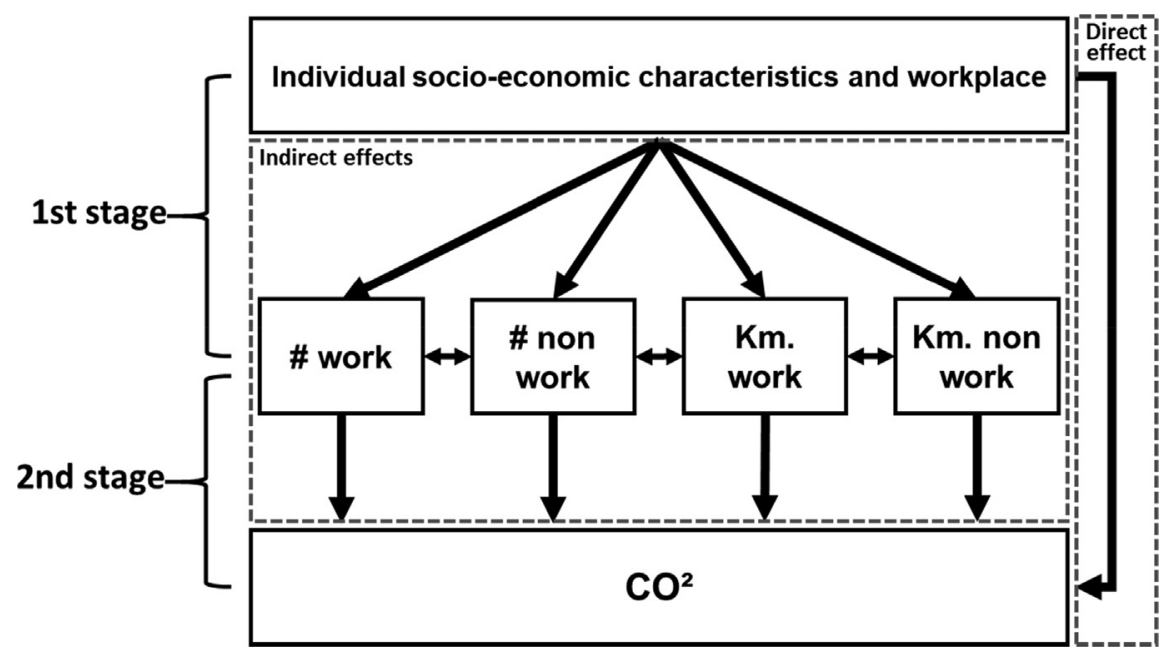

Fig. 1. Conceptual framework.

\section{Results: The determinants of trips made by the working population}

\subsection{Descriptive analysis and co-variance}

Table 2 presents the variables used in the structural equation modeling and their mean values. Variables account for socioeconomic characteristics of the individuals and their households (occupational category, income, gender, age, car access, presence of children, number of adults) and travel patterns (number of trips, kilometers traveled).

The descriptive analysis shows that workers with a fixed workplace report a higher share of walking/biking, as well as higher than average use of public transport. These travel patterns are directly associated with land-use indicators, as workers with a fixed workplace tend to live in high-density areas. Home-based workers report a high share of car use, but they account for a higher share of walking/biking than the average. Moreover, the average distance traveled shows that their trips tend to be local or more clustered at a local scale. Thus, these two groups exhibit lower average $\mathrm{CO} 2$ emissions, with home-based workers displaying a slightly higher level of emissions due to their higher share of car use. In contrast, individuals with a fixed workplace for two days, individuals with multiple workplaces, and teleworkers are shown to be particularly car-dependent. Teleworkers report the highest average CO2 emission levels, directly associated with the average number of work and non-work trips, as well as weekly kilometers traveled. For teleworkers, the high share of car use is directly related to their residential location, which is more often in low density areas. In addition, they report more than average kilometers traveled for both work and non-work trips, entailing high CO2 emission levels. To a lesser extent, workers with multiple workplaces also account for long distances traveled, especially for work-related trips.

Workers with a fixed place of work account for a majority of clerical, full-time employees, earning less than $£ 25,000$. Likewise, homeworkers also account for a higher share of clerical occupations, but they differ from individuals with a single workplace as they are most often self-employed and with a higher average salary. The category of teleworkers has a higher proportion of professional/ managerial occupations, as well as an average higher income, much like workers with a fixed workplace for two consecutive days. Nonetheless, teleworkers are more often self-employed than the latter. In contrast, workers with multiple places of work include a higher proportion of skilled manual workers than average, and self-employed workers. They tend to have slightly higher salaries than people with a fixed workplace.

At the first stage, it is also possible to observe the covariance between the different variables analyzed (Table 3). The covariances are represented by two-way arrows in Fig. 1. The results thus show a trade-off between the number of work trips and the number of non-work trips. This means that workers who make more work trips tend to travel less often for non-work purposes. This result mainly reflects the fact that telecommuters, part-time workers, or even those whose main place of work is home make more out-of- 
Table 2

Characteristics of trips and individuals according to type of workplace.

\begin{tabular}{|c|c|c|c|c|c|}
\hline & Same place & $\begin{array}{l}\text { Same place on at least } 2 \text { consecutive } \\
\text { days }\end{array}$ & Different places & $\begin{array}{l}\text { Home / same building as } \\
\text { home }\end{array}$ & Teleworking \\
\hline \# work trips & 4.3 & 5.4 & 4.5 & 1.6 & 3.7 \\
\hline \# non work trips & 6.5 & 7.1 & 6.2 & 9.5 & 7.6 \\
\hline \# home trips & 8.0 & 8.1 & 7.6 & 8.0 & 7.8 \\
\hline \# total trips & 18.8 & 20.6 & 18.4 & 19.1 & 19.2 \\
\hline$\%$ home trips* & 42.4 & 39.4 & 41.4 & 42.0 & 40.8 \\
\hline $\mathrm{Km}$. work (mean per trip) & 13.8 & 22.3 & 22.2 & 21.5 & 27.0 \\
\hline Km. non work (mean per trip) & 11.1 & 12.8 & 12.2 & 11.3 & 12.9 \\
\hline $\mathrm{Km}$. home (mean per trip) & 12.1 & 17.0 & 16.2 & 12.5 & 17.9 \\
\hline $\mathrm{Km}$. totals (mean per trip) & 12.1 & 16.9 & 16.3 & 12.6 & 17.7 \\
\hline Kg. $\mathrm{CO} 2$ work & 9.4 & 20.3 & 17.4 & 5.9 & 16.7 \\
\hline Kg. CO2 non work & 12.0 & 15.7 & 13.1 & 18.6 & 16.9 \\
\hline Kg. CO2 home & 15.6 & 23.3 & 21.2 & 17.3 & 23.3 \\
\hline Kg. CO2 total & 36.9 & 59.2 & 51.7 & 41.8 & 56.9 \\
\hline Kg. CO2 / km. & 0.16 & 0.17 & 0.17 & 0.17 & 0.17 \\
\hline$\%$ Walk, Bicycle & 8.8 & 6.9 & 6.5 & 8.6 & 8.0 \\
\hline$\%$ Car Driver & 64.5 & 73.0 & 73.7 & 71.6 & 72.2 \\
\hline$\%$ Car Passenger & 14.7 & 10.3 & 11.2 & 13.9 & 9.9 \\
\hline \% Public Transport & 9.6 & 7.6 & 6.6 & 4.3 & 7.9 \\
\hline$\%$ Other & 2.5 & 2.3 & 2.0 & 1.7 & 2.0 \\
\hline$\%$ Professional / managerial & 18.6 & 40.4 & 17.2 & 24.8 & 44.6 \\
\hline$\%$ Clerical & 45.0 & 38.0 & 23.7 & 39.4 & 39.0 \\
\hline$\%$ Skilled manual & 14.0 & 12.4 & 43.4 & 29.1 & 11.8 \\
\hline$\%$ Other manual and other & 22.4 & 9.2 & 15.7 & 6.7 & 4.6 \\
\hline \% Employees: full-time & 73.6 & 77.9 & 50.6 & 23.6 & 57.3 \\
\hline \% Employees: part-time & 22.2 & 12.2 & 12.2 & 13.0 & 11.8 \\
\hline$\%$ Self-employed: full-time & 3.5 & 8.2 & 28.8 & 39.0 & 21.9 \\
\hline$\%$ Self-employed: part-time & 0.8 & 1.7 & 8.4 & 24.3 & 8.9 \\
\hline \% Less than $£ 25,000$ & 68.8 & 41.0 & 61.0 & 62.3 & 37.8 \\
\hline$\% £ 25,000$ to $£ 49,999$ & 25.4 & 40.9 & 30.8 & 25.5 & 38.2 \\
\hline$\% £ 50,000$ and over & 5.9 & 18.1 & 8.2 & 12.2 & 24.0 \\
\hline$\%$ Men & 49.0 & 60.8 & 72.1 & 48.2 & 59.7 \\
\hline$\% 60$ and more & 6.8 & 5.4 & 9.8 & 19.8 & 10.5 \\
\hline$\%$ Main driver & 67.7 & 82.0 & 77.9 & 78.0 & 82.7 \\
\hline$\%$ Only one adult & 11.0 & 13.9 & 10.7 & 11.5 & 13.7 \\
\hline$\%$ One or more child & 35.7 & 37.7 & 38.3 & 38.1 & 39.7 \\
\hline$\%$ Less than 5 persons/hectare & 24.7 & 28.2 & 28.0 & 38.6 & 32.7 \\
\hline$\% 5$ to 75 persons/hectare & 69.2 & 66.4 & 66.1 & 54.8 & 59.4 \\
\hline$\%$ More than 75 persons/hectare & 6.1 & 5.4 & 6.0 & 6.6 & 7.9 \\
\hline \% London Boroughs & 13.1 & 11.5 & 14.4 & 13.3 & 16.2 \\
\hline$\%$ Metropolitan built-up areas & 15.1 & 14.1 & 13.1 & 10.0 & 9.9 \\
\hline \% Large urban (over 250,000) & 16.2 & 17.8 & 15.1 & 13.5 & 15.6 \\
\hline$\%$ Medium urban $(25,000-250,000)$ & 27.8 & 25.7 & 25.3 & 21.6 & 22.4 \\
\hline$\%$ Small/medium urban $(10,000-25,000)$ & 8.1 & 7.9 & 8.3 & 6.6 & 7.7 \\
\hline$\%$ Small urban $(3000-10,000)$ & 6.7 & 7.7 & 7.4 & 7.0 & 7.2 \\
\hline$\%$ Rural & 13.0 & 15.3 & 16.4 & 27.9 & 21.0 \\
\hline \# individuals (weighted) & 87988 & 7218 & 13377 & 4618 & 7255 \\
\hline \# individuals (unweighted) & 81897 & 6837 & 12663 & 4669 & 7087 \\
\hline$\%$ individuals (weighted) & 73.0 & 6.0 & 11.1 & 3.8 & 6.0 \\
\hline
\end{tabular}

Table 3

Covariances between determined variables.

\begin{tabular}{llll}
\hline & \# work trips & \# non work trips & Km. Work (mean) \\
\hline \# non work trips & -1.57 & & \\
Km. Work (mean) & 4.15 & -10.06 & \\
Km. non work (mean) & -2.73 & -5.05 & 18.89
\end{tabular}

*The missing coefficients correspond to non-significant values, $\mathrm{p}<0.001$ 
work trips than those working full-time away from home. In addition, it can be observed that the more commuting trips that are made, the longer they tend to be in terms of kilometers traveled. This may be because part-time workers make fewer work-related trips and have shorter commute distances. However, this particular result counters the findings described in the literature review section regarding telework. It will therefore be necessary to verify the detailed results within the model. Moreover, covariance analysis shows an inverse effect for non-work trips, which tend to be shorter when the number of trips made is higher. This could indicate that individuals who travel more frequently tend to cluster their trips around home, as do individuals who live in highdensity areas, who tend to travel more for non-work purposes. Finally, we observe that the kilometers traveled for work and nonwork trips are positively correlated.

The second stage of the model is based on a single regression, where the dependent variable is $\mathrm{CO} 2$ emission levels, and the independent variables are the number and average distances of work and non-work trips. In addition, all the socio-economic variables included in the previous regressions also act as independent variables. By observing the direct effects of these variables, we can measure all the effects on $\mathrm{CO} 2$ emissions that are not taken into account among the number of trips and kilometers traveled.

Finally, our approach allows for a better understanding of the multiple factors explaining $\mathrm{CO} 2$ emission levels, related to the workplace. The model can be considered as comprehensive, as it introduces indirect effects (through the number of trips and kilometers traveled). A model based on direct effects alone might produce misleading conclusions (De Abreu e Silva and Melo, 2018) since omitting any indirect effects may nullify or lead to adverse effects for some determinants. Or conversely, the direct effects may be amplified by the indirect effects. The results of this work illustrate these different possibilities as well as highlighting the relevance of path analysis within the framework of a more comprehensive approach.

The model obtained is considered a good model with respect to the three indicators generally used for the purpose (Golob, 2003). The root mean square error of approximation (RMSEA) and the standardized root mean square residual (SRMR) are both less than 0.05 , which is judged highly satisfactory. Moreover, the comparative fit index (CFI), which compares the proposed model with an unrestricted base model exhibits a value of 0.99 (a good model should have a value of more than 0.95). The model is therefore well fitted to the data and has good explanatory power.

\subsection{SEM results}

In this section, SEM results are presented in two steps, according to the two levels of the model, as presented in the conceptual framework. The first part emphasizes the determinant factors of work and non-work trips (Table 4). The second part focuses on the direct, indirect, and total effects that explain the $\mathrm{CO} 2$ emission levels according to the type of workplace (Table 5).

\subsubsection{Determinant factors of the number of work trips}

The first regression examines the determinants of the number of weekly work trips (1st column of Table 4). First, it should be noted that workers with different workplaces travel more for work, especially workers who work in the same place for two days. On the other hand, individuals who work from home, fully or partially (home-based workers and teleworkers), travel less for work purposes weekly.

Table 4

Direct effects on weekly travel indicators*

\begin{tabular}{|c|c|c|c|c|c|}
\hline & & \# work trips & $\begin{array}{l}\text { \# non work } \\
\text { trips }\end{array}$ & $\begin{array}{l}\text { Km. work } \\
\text { (mean) }\end{array}$ & $\begin{array}{l}\text { Km. non work } \\
\text { (mean) }\end{array}$ \\
\hline \multirow[t]{4}{*}{ Type of workplace (ref: Same place) } & $\begin{array}{l}\text { Same place on at least } 2 \text { consecutive } \\
\text { days }\end{array}$ & 0.77 & 0.37 & 5.14 & 0.81 \\
\hline & Different places & 0.14 & & 6.30 & 0.96 \\
\hline & Home / same building as home & -2.55 & 2.33 & & \\
\hline & Teleworking & -0.82 & 0.74 & 9.01 & 1.14 \\
\hline \multirow[t]{3}{*}{ Socio Economic Group (ref: Clerical) } & Professional / managerial & 0.44 & -0.22 & 2.12 & 0.67 \\
\hline & Skilled manual & -0.35 & -0.62 & -2.82 & -1.21 \\
\hline & Other manual and other & & -0.63 & -3.21 & -1.42 \\
\hline \multirow[t]{3}{*}{ Working status (ref: Employees: full-time) } & Employees: part-time & -1.22 & 1.96 & -3.51 & -0.85 \\
\hline & Self-employed: full-time & 0.16 & -0.18 & -4.63 & \\
\hline & Self-employed: part-time & -1.34 & 2.35 & -6.50 & \\
\hline \multirow{2}{*}{$\begin{array}{l}\text { Individual income (ref: } £ 25,000 \text { to } \\
£ 49,999 \text { ) }\end{array}$} & Less than $£ 25,000$ & & -0.15 & -4.18 & -1.37 \\
\hline & $£ 50,000$ and over & & -0.33 & 4.69 & 1.04 \\
\hline Gender & Men & 0.37 & -1.24 & 4.44 & 0.64 \\
\hline Age & 60 and over & -0.32 & & -2.07 & \\
\hline Density & Person/ha. & & -0.01 & & -0.01 \\
\hline Area Type & Urban - > Rural & & & 0.99 & 0.86 \\
\hline Car access & Main driver & 0.49 & 2.79 & 2.99 & 0.93 \\
\hline Type of household & Only one adult & & 0.36 & -0.74 & \\
\hline Type of household & One or more child & 0.33 & -1.67 & 0.40 & 1.93 \\
\hline
\end{tabular}

* The missing coefficients correspond to non-significant values. 
Table 5

Indirect, Direct, and Total effects on CO2 emissions.

\begin{tabular}{|c|c|c|c|c|c|c|c|}
\hline \multirow[t]{2}{*}{ Variable } & \multirow[t]{2}{*}{ Category } & \multicolumn{4}{|c|}{ Indirect effects } & \multirow[t]{2}{*}{ Direct effect } & \multirow[t]{2}{*}{ Total effects } \\
\hline & & \# work & \# non work & Km. work & $\begin{array}{l}\text { Km. non } \\
\text { work }\end{array}$ & & \\
\hline \multirow[t]{4}{*}{ Type of workplace (ref: Same place) } & $\begin{array}{l}\text { Same place on at least } 2 \\
\text { consecutive days }\end{array}$ & 1.91 & 0.83 & 5.61 & 0.74 & 4.02 & 13.11 \\
\hline & Different places & 0.35 & & 6.88 & 0.88 & 4.38 & 12.50 \\
\hline & Home / same building as home & -6.29 & 5.16 & & & 3.19 & 2.06 \\
\hline & Teleworking & -2.02 & 1.63 & 9.85 & 1.04 & & 10.50 \\
\hline \multirow[t]{3}{*}{ Socio Economic Group (ref: Clerical) } & Professional / managerial & 1.09 & -0.49 & 2.32 & 0.61 & 1.52 & 5.05 \\
\hline & Skilled manual & -0.86 & -1.38 & -3.08 & -1.11 & 0.97 & -5.45 \\
\hline & Other manual and other & & -1.38 & -3.51 & -1.30 & & -6.19 \\
\hline \multirow{3}{*}{$\begin{array}{l}\text { Working status (ref: Employees: full- } \\
\text { time) }\end{array}$} & Employees: part-time & -3.00 & 4.34 & -3.83 & -0.78 & & -3.28 \\
\hline & Self-employed: full-time & 0.39 & -0.40 & -5.06 & & & -5.07 \\
\hline & Self-employed: part-time & -3.32 & 5.20 & -7.10 & & & -5.22 \\
\hline \multirow{2}{*}{$\begin{array}{l}\text { Individual income (ref: } £ 25,000 \text { to } \\
\qquad 49,999 \text { ) }\end{array}$} & Less than $£ 25,000$ & & -0.33 & -4.56 & -1.25 & -1.59 & -7.73 \\
\hline & $£ 50,000$ and over & & -0.74 & 5.12 & 0.96 & -2.23 & 3.11 \\
\hline Gender & Men & 0.92 & -2.74 & 4.85 & 0.59 & 3.81 & 7.43 \\
\hline Age & 60 and over & -0.78 & & -2.26 & & & -3.05 \\
\hline Density & Person/ha. & & -0.03 & & -0.01 & -0.05 & -0.09 \\
\hline Area Type & Urban - > Rural & & & 1.08 & 0.78 & 1.44 & 3.30 \\
\hline Car access & Main driver & 1.21 & 6.17 & 3.27 & 0.85 & 9.59 & 21.10 \\
\hline Type of household & Only one adult & & 0.79 & -0.81 & & -2.06 & -2.08 \\
\hline Type of household & One or more child & 0.80 & -3.70 & 0.44 & 1.77 & & -0.69 \\
\hline
\end{tabular}

Findings also show that workers with professional and managerial functions make more work-related trips than clerical workers. In contrast, skilled manual workers travel less for work purposes. In addition, the number of weekly work trips depends on the working status of individuals: part-time workers make fewer work-related trips than other categories. Finally, the regression points out that the profile of workers with the highest probability of having a large number of weekly trips for work are men, on low incomes, aged under 60, who are the main drivers of a car, and part of a household with at least one child.

\subsubsection{Determinant factors of the number of non-work trips}

The effects of the socio-economic characteristics of workers on the number of non-work trips (2nd column of Table 4) are often the contrary of the effects observed for the number of work-related trips. For part-time workers, a trade-off is observed between the number of work trips and the number of non-work trips. Thus, part-time workers tend to report a particularly high number of nonwork trips. This is also the case for home-based workers. The latter make very few work-related trips (if any), but they tend to compensate by traveling more for non-work purposes. Also, teleworkers report a higher number of non-work trips than the average. In contrast, for workers with the same workplace for two days, the higher number of non-work trips does not entail fewer work trips.

Moreover, the model shows that all occupational categories travel less for non-work purpose than the reference category (clerical workers) and these effects are even more accentuated for skilled manual or other skilled workers. Thus, there are no trade-off effects between work and non-work trips. Overall, women, main drivers of a vehicle, individuals living in high-density areas, and people without children tend to make more non-work trips than the average.

\subsubsection{Determinant factors of average kilometers traveled for work}

Regarding average kilometers traveled for work (3rd column of Table 4), there is a contrast between workers with a fixed workplace, as well as home-based workers, and workers with multiple workplaces including teleworkers, workers with a fixed workplace for two days, and workers with different workplaces. For the former the average distance traveled is shorter, while for the latter the distances are greater, especially for teleworkers. In addition, results show that professional/managerial groups are those that report the longest commuting distances, while skilled manual workers have shorter commutes. Also, compared to full-time workers, all other categories (part-time workers and self-employed) travel shorter distances for work purposes. Finally, the probability of traveling longer distances for work is higher for men, high-income workers, main drivers of a vehicle, individuals who are part of households with children, and people living in rural areas.

\subsubsection{Determinant factors of average kilometers traveled for non-work purposes}

The effects of the main determinants on average kilometers traveled for non-work purposes (4th column of Table 4) are similar to those observed for average work trip distances. There is also a contrast between workers with a fixed workplace or home-based workers, who report fewer kilometers traveled for non-work purposes than do workers with multiple workplaces. Professional/ managerial workers report the most kilometers traveled for non-work purposes, in contrast to skilled manual workers. Also, regarding working status, part-time workers report shorter average distances for non-work trips than do other categories. Overall, men on highincomes who are the main drivers of a vehicle and have children and individuals living in low-density/rural areas tend to travel the longest distances for non-work purposes. 


\subsubsection{Direct, indirect, and total effects on $\mathrm{CO} 2$ emissions}

This final results table shows the results of the last regression, explaining the $\mathrm{CO} 2$ emissions of workers. The determinants are the same as for the previous regressions to which were added the four variables previously determined, namely the number and average distances of travel for work and for non-work trips. As the SEM is able to model several endogenous variables and handles both direct and indirect relationships between them. Table 5 includes direct effects and indirect effects which are the sum of the effects mediated by the variable above. The last column shows the total effect, which is the sum of the direct and indirect effects.

Unsurprisingly the factor that affects $\mathrm{CO} 2$ emissions most is being the main driver of a car, the effect being greater than for the other determinants. Regarding car access, the direct effect seems to be the most significant as it relates directly to the mode of transport actually used (which is one of the travel characteristics not specifically taken into account in the model). Moreover, car access effects show that the increased number of non-work trips weighs heavily on $\mathrm{CO} 2$ emission levels of main drivers, followed by the average distance and the number of work trips.

Secondly, the model emphasizes that the type of workplace has significant effects on $\mathrm{CO} 2$ emissions. It is interesting to note that the greatest effect is observed for workers with multiple workplaces, as well as workers with a fixed workplace for at least two days. Regarding the type of workplace, the average kilometers traveled for work purposes, which is directly related to the mode of transport used, has the most significant effect on the carbon footprint of workers. The effects related to the number of work trips and the average kilometers traveled for non-work trips are less significant. In addition, teleworkers are associated with high CO2 emission levels, due mainly to average kilometers traveled for work and, to a lesser extent, the number of non-work trips and the average kilometers traveled for those trips. In addition, for teleworkers the effect of the number of work trips on $\mathrm{CO} 2$ emissions is negative, as expected. Nonetheless, this negative effect does not prevent teleworkers from having one of the highest CO2 emission levels. On the other hand, home-based workers report one of the lowest carbon footprints, although it is still higher than for workers with a single workplace. In fact, home-based workers report few work-related trips, but we observe a trade-off effect with the number of non-work trips.

Moreover, the results of the model show that professional/managerial workers report higher CO2 emissions levels than skilled manual workers. Their carbon footprint is directly related to average kilometers traveled for work, modal share, and the number of weekly work-related trips. Conversely, for skilled manual workers the effects are significantly lower than for the reference category. Part-time workers report lower emission levels due to fewer commutes and shorter average commuting distances for work. However, part-time workers report a trade-off between work and non-work trips, much as for home-based workers.

The model also demonstrates that high-income workers have higher $\mathrm{CO} 2$ emissions associated with higher average kilometers traveled for both work and non-work purposes. In contrast, the lower carbon footprint of low-income workers is explained by average kilometers traveled and, to a lesser extent, the modes of transport used and the number of non-work trips.

Second, the model shows that men's carbon footprints are higher than women's due to kilometers traveled for work, mode of transport, and number of work-related trips. Finally, workers who are part of households with children are responsible for lower CO2 emission levels for travel for non-work purposes, although they display longer average distances for work and non-work trips combined.

\section{Discussion}

This study developed a Structural Equation Modeling approach using individual and household level data from the National Travel Survey (NTS) to shed light on the diversification of workplaces and its impacts on travel behavior and CO2 emissions in the United Kingdom. We advocate that, with the continuous decrease over the past two decades in the proportion of individuals with a fixed workplace, it is important to capture both the recent shifts in travel patterns and their environmental impact. We also hypothesize that the development of ICT and the consequent increase in the proportion of home-based workers and teleworkers does not necessarily generate fewer $\mathrm{CO} 2$ emissions due to potential rebound effects. The main findings of this study are noteworthy for policymakers, as current urban travel demand forecasting practice and environmental policies rarely consider work location (in-home or out-of-home) or employment type as explanatory variables. It is also important to note that there are some complexities and limitations in the analysis. While we find that non-traditional working arrangements are associated with higher CO2 emissions, this is based on a cross-sectional analysis. In order to definitely prove the existence of a "rebound effect", one would probably need longitudinal data - e.g., to demonstrate the effect on distance traveled by car/ CO2 of transitioning from a traditional arrangement to teleworking.

The model developed in this study aims at analyzing the complex relationship between workplace and CO2 emissions beyond direct effects. The methodological approach introduces a comprehensive study of travel behavior, trade-off effects, and work and non-work trips by breaking down and distinguishing travel characteristics that influence $\mathrm{CO} 2$ emissions. Thus, the model reveals the many interactions between workers, workplace, and travel patterns. For instance, although CO2 emissions for teleworkers and workers with multiple workplaces are mainly related to kilometers traveled for work, the findings show non-work trips also have a significant environmental impact for the former. Similarly, home-based workers account for slightly higher levels of CO2 emissions than workers with a single workplace because their non-work-related travel offsets the absence of regular commuting trips. Therefore, the comprehensive approach and findings introduced by the SEM calls for an in-depth discussion of GHG reduction policies.

The model demonstrates the key effects of socio-economic characteristics and travel behavior over CO2 emissions. First, we observe that $\mathrm{CO} 2$ emission levels are considerably higher than other determinants for individuals with multiple work places. These levels are mainly associated with total work kilometers traveled per week, but also direct effects, such as modal share and car access. 
Results show that, overall, the diversification of the workplace is reflected by longer average distances for work trips, which are often associated with more distant residential locations. For teleworkers, $\mathrm{CO} 2$ emissions are more closely related to distances traveled to work: they tend to live further away and have longer commuting distances. To a lesser extent, the trade-off observed between work and non-work trips also affects the total $\mathrm{CO} 2$ emissions for individuals who telework. For home-based workers, the effects are more directly related to trade-off effects between work and non-work travel. Secondly, car access also appears to be a significant factor, not only because the automobile is a highly polluting mode of transportation, but also because its use reflects longer distances traveled for work. Part-time workers are associated with lower CO2 emissions because they travel shorter distances for work trips, indicating that they live closer to their workplace. Moreover, the model confirms some expected findings: men, on high-incomes and who are skilled are responsible for higher $\mathrm{CO} 2$ emission levels as they tend to travel longer distances, particularly for work trips. Men in particular display more significant direct effects, possibly because they use cars more than women do.

Moreover, an original contribution from this paper is that it highlights the effects of non-work trips on total weekly travel. Current urban travel policies are constructed mostly on the basis of studies focusing on commuting trips and neglect the effects of non-work activities on travel behavior. Thus, the use of a seven-day trip diary overcomes some of the limitations with one-day trip diaries, which tend to overlook the majority of non-work trips or trade-off effects. Contrary to the generally accepted idea that commuting trips have a greater environmental impact, the findings of this study show that non-work trips account for a significant share of $\mathrm{CO} 2$ emissions.

\subsection{Policy implications}

The recent development of telework arrangements is directly related to residential location: as highlighted in the literature review section, the NTS database confirms that teleworkers tend to live further from central business districts, resulting in significant car dependency and longer commute distances. Some recent studies, such as Shabanpour et al.'s, (2018) have made a case for teleworking policies, showing through an activity-based model that they have the potential to reduce network congestion and vehicular emissions specifically during rush hours. Our results show that although planners and policymakers have hypothesized that the development of telework could potentially reduce travel demand, those forecasts remain largely unmet. These opposite results could be due to several factors: the first study considers all frequencies of telework, while our approach takes into account individuals who telework at least once a week. Moreover, the 7-day trip diary allows to better understanding the full-array of non-work trips. Finally, the differences between the American and British contexts should be considered: we could hypothesize that American teleworkers are more likely to commute by car, thus telecommuting would have a more significant impact on GHG emissions.

The model shows that, in the United Kingdom, individuals who telework seem to have a greater impact on CO2 emissions than individuals with a fixed work location. The environmental impact is directly related to total weekly kilometers traveled for both work and non-work trips. As previously noted, rebound effects cancel out the positive effects of teleworking or further increase GHG emissions because more kilometers are traveled. With the increasing development of technological progress, we may expect that more workers will opt for telecommuting and that travel-behavior related to this practice will increase: "It appears that without holistic consideration of the options and potential outcomes for GHG reduction policies, anticipated decreases in some arenas will permit increases in other types of travel behavior in the form of substitution effects." (Zhu and Mason, 2014, p.11). Moos et al. (2006) suggest that policies aimed at decreasing automobile commuting so as to limit harmful emissions might not be effective if they are thought about individually. Thus, it is important to understand that many environmental effects of the development of ICT arise through a compound set of individual adjustments.

The model also reveals that, although home-based workers report fewer work-related trips weekly, they still exert a greater effect on $\mathrm{CO} 2$ emissions than workers with a fixed workplace. As with the results observed for the category of teleworkers, part of the commuting trips avoided by home-based workers are converted into personal or non-work trips. Therefore, although the average journey of home-based workers tends to be shorter and clustered around home, a significant environmental impact is still perceived, suggesting a higher proportion of car use. Likewise, the results emphasize that individuals with multiple work locations tend to report significant effects on $\mathrm{CO} 2$ emissions. Unlike the previous two categories of workers discussed, their environmental impact is mostly associated with work-related trips. It is interesting to note that the number of their work trips per week is only slightly higher than for workers with a fixed workplace, but they account for the longest total work kilometers traveled weekly. Most policies fail to consider that a proportion of workers have multiple workplaces, and that this often entails travel patterns that are less regular, more variable, and may require significant flexibility in terms of travel behavior, as well as car dependency.

Thus, GHG emission reduction policies should be implemented at different levels and scales. It is important to note that, in a context of strong overall growth in rail use in the UK, public transport services need to respond adequately to changing demands arising in the context of the growing diversification of workplaces. First, we note that the travel patterns observed for home-based workers, mainly clustered around a local scale, call for policies that encourage the use of environmentally-friendly modes of transport, such as electrically assisted cycles. As this category of workers is already more likely to cycle than their counterparts, such policies could reduce the automobile dependency of workers living in low-density areas. As far as teleworkers are concerned, a comprehensive approach to both work and non-work trips should be considered while devising GHG emission reduction policies. First, it is important to tackle long commuting distances by encouraging the increase in the modal share of public transport (e.g., long-distance rail). Thus, the implementation of telework in companies could be accompanied by incentives to increase public transit use and multimodality. Multimodality should be studied carefully, though, since Heinen and Mattioli (2019) demonstrate its limited impacts in terms of $\mathrm{CO} 2$ emissions and environmental policies in the transport sector. The authors also demonstrate that multimodal trips tend to have higher $\mathrm{CO} 2$ emissions than unimodal trips. It is emphasized that high emissions levels are more related to high 
levels of travel activity, which should be the main focus of transport policies. In addition, policies designed to reduce emissions from non-work trips could be introduced in a similar fashion as the recommendations made for home-based workers. Nonetheless, GHG emissions of individuals with multiple places of work are more challenging to address through transport policies: their weekly travel patterns are more flexible and varied than those of other categories of workers. Often, they do not have a regular commuting pattern, which entails significant car dependency.

In conclusion, this paper presents a novel exploration of the relationship between workplace and travel behavior by comparing different categories of workers by workplace. Thus, more comprehensive transportation and environmental policies should be considered in order to tackle travel planning in the light of the increasingly diverse and complex travel patterns of the labor force. The discussion emphasizes the importance of capturing the full array of trade-off effects, as well as demonstrating the potential range of travel patterns that vary with individual characteristics and preferences. It seems that specific climate-mitigation transport policies fall victim to unexpected changes in travel behavior because new possibilities arising from the development of ICT allow individuals to drive longer distances and emit more GHG. In view of the results found here and the growing diversification of the workplace, advances in policy making with respect to sustainability should be extending the scope of travel-behavior impacts.

\section{Acknowledgements}

This research was funded by the Mobile Lives Forum, as part of its research program on mobility transition. The Mobile Lives Forum is a research and prospective institute created by SNCF (France).

The NTS special license dataset of the UK Department of Transport was kindly provided by the UK Data Service.

\section{References}

Aguilera, A., Massot, M.-H., Proulhac, L., 2009. Exploring the relationship between work and travel behavior on weekdays: analysis of Paris region travel survey over 20 years. Transp. Res. Rec. 2135, 69-77. https://doi.org/10.3141/2135-09.

Armoogum, J., Bonsall, P., Browne, M., Christensen, L., Cools, M., Cornélis, E., Diana, M., Guilloux, T., Harder, H., Hegner Reinau, K., Hubert, J.-P., Kagerbauer, M., Kuhnimhof, T., Madre, J.-L., Moiseeva, A., Polak, J., Schultz, A., Tébar, M., Vidalakis, L., 2014. Survey Harmonisation with New Technologies Improvement, SHANTI. IFSTTAR, Marne-la-Vallée.

Astroza, S., Bhat, P.C., Bhat, C.R., Pendyala, R.M., Garikapati, V.M., 2018. Understanding activity engagement across weekdays and weekend days: A multivariate multiple discrete-continuous modeling approach. J. Choice Modell. 28, 56-70. https://doi.org/10.1016/j.jocm.2018.05.004.

Axhausen, K.W., Zimmermann, A., Schönfelder, S., Rindsfüser, G., Haupt, T., 2002. Observing the rhythms of daily life: A six-week travel diary. Transportation 29, 95-124.

Baker, K.J., Rylatt, R.M., 2008. Improving the prediction of UK domestic energy-demand using annual consumption-data. Appl. Energy 85, 475-482. https://doi.org/ 10.1016/j.apenergy.2007.09.004.

Choo, S., Mokhtarian, P.L., Salomon, I., 2005. Does telecommuting reduce vehicle-miles traveled? An aggregate time series analysis for the U.S. Transportation 32, 37-64. https://doi.org/10.1007/s11116-004-3046-7.

De Abreu e Silva, J., Melo, P.C., 2018. Home telework, travel behavior, and land-use patterns: A path analysis of British single-worker households. JTLU 11. 10.5198/ jtlu.2018.1134.

Ettema, D., 2010. The impact of telecommuting on residential relocation and residential preferences: A latent class modelling approach. J. Transport Land Use 3, 7-24.

Fan, Y., 2017. Household structure and gender differences in travel time: spouse/partner presence, parenthood, and breadwinner status. Transportation 44 (2), $271-291$.

Felstead, A., 2012. Rapid change or slow evolution? Changing places of work and their consequences in the UK. J. Transp. Geogr. 21, 31-38. https://doi.org/10.1016/ j.jtrangeo.2011.10.002.

Golob, T.F., 2003. Structural equation modeling for travel behavior research. Transport. Res. Part B: Methodol. 37, 1-25.

Gordon, P., Kumar, A., Richardson, H.W., 1989. Gender differences in metropolitan travel behaviour. Regional Stud. 23 (6), $499-510$.

Hanson, S., 1980. The importance of the multi-purpose journey to work in urban travel behavior. Transportation 9, 229-248. https://doi.org/10.1007/BF00153866.

He, S.Y., Hu, L., 2015. Telecommuting, income, and out-of-home activities. Travel Behav. Soc. 2.

Heinen, E., Mattioli, G., 2019. Multimodality and CO2 emissions: A relationship moderated by distance. Transport. Res. Part D: Transport Environ. 75, 179-196.

Helminen, V., Ristimäki, M., 2007. Relationships between commuting distance, frequency and telework in Finland. J. Transp. Geogr. 15, 331-342. https://doi.org/10. 1016/j.jtrangeo.2006.12.004.

Koroma, J., Hyrkkänen, U., Vartiainen, M., 2014. Looking for people, places and connections: hindrances when working in multiple locations: a review. New Technol., Work Employment 29, 139-159. https://doi.org/10.1111/ntwe.12030.

Lesnard, L., Kan, M.Y., 2011. Investigating scheduling of work: a two-stage optimal matching analysis of workdays and workweeks: Investigating Scheduling of Work. J. Royal Statist. Soc.: Ser. A (Statist. Soc.) 174 (2), 349-368.

Mattioli, G., Anable, J., 2017. Gross polluters for food shopping travel: An activity-based typology. Travel Behav. Soc. 6, 19-31. https://doi.org/10.1016/j.tbs.2016. 04.002 .

Melo, P.C., de Abreu e Silva, J., 2017. Home telework and household commuting patterns in Great Britain. Transport. Res. Part A: Pol. Pract. 103, 1-24. 10.1016/j.tra. 2017.05.011.

Mokhtarian, P., 2009. If telecommunication is such a good substitute for travel, why does congestion continue to get worse? Transport. Lett. 1, 1-17. https://doi.org/ 10.3328/TL.2009.01.01.1-17.

Mokhtarian, P.L., Henderson, D., 2000. Analyzing the Travel Behavior of Home-Based Workers in the 1991 CALTRANS Statewide Travel Survey.

Moos, M., Andrey, J., Johnson, L.C., 2006. The sustainability of telework: an ecological-footprinting approach. Sustain.: Sci. Pract. Policy 2, 3-14. https://doi.org/10. 1080/15487733.2006.11907973.

Ory, D.T., Mokhtarian, P.L., 2006. Which came first, the telecommuting or the residential relocation? An empirical analysis of causality. Urban Geogr. 27, 590-609. https://doi.org/10.2747/0272-3638.27.7.590.

Pas, E.I., Koppelman, F.S., 1987. An examination of the determinants of day-to-day variability in individuals' urban travel behavior. Transportation 14, 3-20. https:// doi.org/10.1007/BF00172463.

Pendyala, R.M., Goulias, K.G., Kitamura, R., 1991. Impact of telecommuting on spatial and temporal patterns of household travel. Transportation 18, 383-409. https://doi.org/10.1007/BF00186566.

Ravalet, E., Rerat, P., 2019. Télétravail et mobilité : pour le meilleur et pour le pire? Étude de cas en Suisse. Presented at the 2e Rencontres Francophones Transport Mobilité (RFTM), Montréal.

Schieman, S., Young, M., 2010. Is there a downside to schedule control for the work-family interface? J. Fam. Issues 31, 1391-1414 10/frtpqn.

Shabanpour, R., Golshani, N., Tayarani, M., Auld, J., Mohammadian, A., 2018. Analysis of telecommuting behavior and impacts on travel demand and the 
environment. Transport. Res. Part D: Transport Environ. 62, 563-576. https://doi.org/10.1016/j.trd.2018.04.003.

Soo, J., Ettema, D., Ottens, H.F.L., 2008. Analysis of Travel Time in Multiple-Purpose Trips: Transportation Research Record. $10.3141 / 2082-07$.

Tarigan, A.K.M., Kitamura, R., 2009. Week-to-Week Leisure Trip Frequency and Its Variability: Transportation Research Record. 10.3141/2135-06.

Volosin, S.E., Paul, S., Christian, K.P., Konduri, K.C., Pendyala, R.M., 2013. Exploring the dynamics in travel time frontiers. Transp. Res. Rec. 2382, 20-27. https://doi. org/10.3141/2382-03.

Westelius, O., 1973. The individual's way of choosing between alternative outlets. National Swedish Institute for Building Research, Stockholm.

Yen, J.-R., 2000. Interpreting employee telecommuting adoption: An economics perspective. Transportation 27, 149-164. 10/dx5f46.

Zhu, P., 2013. Telecommuting, household commute and location choice. Urban Stud. 50, 2441-2459. https://doi.org/10.1177/0042098012474520.

Zhu, P., 2012. Are telecommuting and personal travel complements or substitutes? Ann. Reg. Sci. 48, 619-639. https://doi.org/10.1007/s00168-011-0460-6.

Zhu, P., Mason, S.G., 2014. The impact of telecommuting on personal vehicle usage and environmental sustainability. Int. J. Environ. Sci. Technol. 11, 2185-2200. https://doi.org/10.1007/s13762-014-0556-5. 